\title{
Association of $C D 40$ with rheumatoid arthritis confirmed in a large UK case-control study
}

\author{
Gisela Orozco, ${ }^{1}$ Steve Eyre, ${ }^{1}$ Anne Hinks, ${ }^{1}$ Xiayi Ke, ${ }^{1}$ Wellcome Trust Case Control \\ Consortium, YEAR consortium, Anthony G Wilson, ${ }^{2}$ Deborah E Bax, ${ }^{2}$ Ann W Morgan, ${ }^{3}$ \\ Paul Emery, ${ }^{3}$ Sophia Steer, ${ }^{4}$ Lynne Hocking, ${ }^{5}$ David M Reid, ${ }^{5}$ Paul Wordsworth, ${ }^{6}$ \\ Pille Harrison, ${ }^{6}$ Wendy Thomson, ${ }^{1}$ Anne Barton, ${ }^{1}$ Jane Worthington ${ }^{1}$
}

\begin{abstract}
- Additional data
(supplementary information and supplementary tables) are published online only at http:// ard.bmj.com/content/vol69/ issue5

${ }^{1}$ arc Epidemiology Unit, The University of Manchester,

Manchester, UK

${ }^{2}$ School of Medicine and

Biomedical Sciences, The

University of Sheffield,

Sheffield, UK

${ }^{3}$ NIHR Leeds Musculoskeletal Biomedical Research Unit,

Leeds Institute of Molecular

Medicine, University of Leeds,

Leeds, UK

${ }^{4}$ Clinical and Academic

Rheumatology, Kings College

Hospital NHS Foundation Trust,

Denmark Hill, London, UK

${ }^{5}$ Bone Research Group,

Department of Medicine and

Therapeutics, University of

Aberdeen, UK

${ }^{6}$ University of Oxford Institute of Musculoskeletal Sciences,

Botnar Research Centre,

Oxford, UK
\end{abstract}

\section{Correspondence to \\ Dr Gisela Orozco, arc \\ Epidemiology Unit, Faculty of Medical and Human Sciences, University of Manchester, Stopford Building, Oxford Road, Manchester M13 9PT, UK; gisela.orozco@manchester. ac.uk}

Accepted 3 May 2009

Published Online First

11 May 2009

\section{ABSTRACT}

Objective A recent meta-analysis of published genomewide association studies (GWAS) in populations of European descent reported novel associations of markers mapping to the CD40, CCL21 and CDK6 genes with rheumatoid arthritis (RA) susceptibility while a largescale, case-control association study in a Japanese population identified association with multiple single nucleotide polymorphisms (SNPs) in the CD244 gene. The aim of the current study was to validate these potential RA susceptibility markers in a UK population.

Methods A total of 4 SNPs (rs4810485 in CD40, rs2812378 in CCL21, rs42041 in CDK6 and rs6682654 in CD244) were genotyped in a UK cohort comprising 3962 UK patients with RA and 3531 healthy controls using the Sequenom iPlex platform. Genotype counts in patients and controls were analysed with the $\chi^{2}$ test using Stata. Results Association to the CD40 gene was robustly replicated ( $p=2 \times 10^{-4}$, OR $0.86,95 \% \mathrm{Cl} 0.79$ to 0.93 ) and modest evidence was found for association with the CCL21 locus ( $p=0.04$, OR 1.08, 95\% Cl 1.01 to 1.16). However, there was no evidence for association of rs42041 (CDK6) and rs6682654 (CD244) with RA susceptibility in this UK population. Following a metaanalysis including the original data, association to CD40 was confirmed $\left(p=7.8 \times 10^{-8}\right.$, OR 0.87 (95\% Cl 0.83 to 0.92).

Conclusion In this large UK cohort, strong association of the CD40 gene with susceptibility to RA was found, and weaker evidence for association with RA in the CCL21 locus.

\section{INTRODUCTION}

Genome-wide association studies (GWAS) have led to a breakthrough in the search for complex disease susceptibility markers. ${ }^{1}$ Specifically for rheumatoid arthritis (RA), these studies have detected a number of new susceptibility loci, including the 6q23, ${ }^{2-4}$ TRAF1/C5, ${ }^{5-9}$ PRKCQ, KIF5A and $I L 2 R B$ genetic regions. ${ }^{10}$ Recently, a meta-analysis of the Wellcome Trust Case Control Consortium (WTCCC) GWAS and a US GWAS ${ }^{5}$ confirmed association to PRKCQ, KIF5A and MMEL and identified additional RA-associated markers mapping to the CD40, CCL21 and CDK6 loci, ${ }^{11}$ that have yet to be confirmed in an independent UK population. In addition, a recent case-control association study in a Japanese population identified two functional variants mapping to the CD244 gene, rs3766379 and rs6682654, that were associated with RA, again yet to be tested for association in a UK population. ${ }^{12}$
These studies therefore add to the recent explosion in the number of loci reported to be associated with RA susceptibility. In order for these loci to be confirmed as risk factors for RA, well powered validation studies are required to support these initial findings.

The aims of this study were, therefore, first to validate the additional RA markers derived from the recent meta-analysis (CD40, CCL21 and CDK6) in an independent UK population and, second, to investigate a functional CD244 variant reported to be associated with RA in the Japanese study. ${ }^{11} 12$

\section{METHODS}

Patients with RA ( $\mathrm{n}=3962)$ were recruited from six centres (Manchester, Sheffield, Leeds, Aberdeen, Oxford and London) across the UK. All patients were Caucasian of North European ancestry and all fulfilled the 1987 American College of Rheumatology classification criteria modified for genetic studies. ${ }^{13} 14$ Clinical and demographic characteristics of the cohort are detailed in supplementary table 1 . Briefly, $71.8 \%$ participants were women, $72.1 \%$ were rheumatoid factor positive and $67.9 \%$ carried anti-citrullinated protein antibodies (ACPA) as recognised by the anti-cyclic citrullinated protein (CCP) antibody test. This cohort is therefore representative of a hospital-based series of patients with RA. Autoantibody status data was available for 3723 and 2281 patients for rheumatoid factor (RF) and anti-CCP, respectively. Healthy controls ( $n=3531$ ) were recruited from five of the six centres (patients only recruited from London). All participants were recruited after providing informed consent and the study was approved by the North West Research Ethics Committee (MREC 99/8/84).

Genotyping was performed using the Sequenom iPlex platform (http://www.sequenom.com) according to the manufacturer's instructions. All genotyping was performed at the arc Epidemiology Unit, Manchester. Only samples and single nucleotide polymorphisms (SNPs) exceeding a $90 \%$ success rate were used in the analysis.

Genotype counts in patients and controls were analysed using Stata software (Stata, College Station, Texas, USA) with the $\chi^{2}$ test. For the meta-analysis, the Breslow-Day test for homogeneity and the Cochran Mantel-Haenszel test were performed using Stata. For all the tests performed, $p$ values $<0.0125$ were considered statistically significant, after applying Bonferroni correction for four comparisons. online under the BMJ Journals unlocked scheme, see http:// ard.bmj.com/info/unlocked.dtl 
Power calculations were performed using the Quanto V.0.5 software (Department of Preventive Medicine University of Southern California, California, USA), considering minor allele frequencies and ORs similar to those found in previous studies 451112 at the 5\% significance level.

\section{RESULTS}

We selected four polymorphisms previously reported as RA susceptibility markers for testing in the current study:

(1) rs4810485, located in the second intron of the CD40 gene;

(2) rs2812378, mapping to the 5' untranslated region of CCL21;

(3) rs42041, positioned in a CDK6 intron ${ }^{11}$;

(4) rs6682654, located in CD244, which is an almost perfect proxy of the functional RA marker for the Japanese population within this gene, rs3766379 $\left(\mathrm{D}^{\prime}=1, \mathrm{r}^{2}=0.97\right) .{ }^{12}$

Genotype frequencies conformed to Hardy-Weinberg expectations in patients and controls for all the polymorphisms under study. The estimated power of the study was $86 \%$ for rs $481048,77 \%$ for rs $2812378,60 \%$ for rs 42041 and $99 \%$ for rs6682654.

Table 1 shows the results of this validation study. Allele frequencies were similar to those previously described in a US population for the CD40, CCL21 and CDK6 markers. ${ }^{11}$ We found that the minor $\mathrm{T}$ allele of CD40 rs4810485 was significantly increased in healthy controls compared to patients with RA ( $p=2 \times 10^{-4}$, OR $0.86,95 \%$ CI 0.79 to 0.93$)$. This is in accordance with the previous study by Raychaudhuri et al.

When we analysed CCL21 rs2812378, we observed a higher frequency of the minor $C$ allele in patients with $\mathrm{RA}$ as previously described, ${ }^{11}$ although this skewing seemed to have a more modest effect in our population ( $p=0.04$, OR 1.08, 95\% CI 1.01 to 1.16). With regard to CDK6 rs42041, no evidence of association with RA was found in our UK population (table 1).

Additionally, we examined the functional CD244 variant rs6682654, which was previously shown to be associated with RA in a Japanese population. ${ }^{12}$ Linkage disequilibrium (LD) between this SNP and the other marker within CD244, rs3766379, also reported to be associated with RA in the Japanese study, is higher in the Caucasian population $\left(r^{2}=0.97\right.$, $\left.\mathrm{D}^{\prime}=1\right)$ than in the Japanese population $\left(r^{2}=0.87, \mathrm{D}^{\prime}=1\right) .{ }^{15}$ When we compared the distribution of allele and genotype frequencies of rs6682654 between patients and controls, we did not find statistically significant differences (table 1). Allele frequencies of the reference $G$ allele were lower in the UK population than in the previously described Japanese population $(0.43$ and 0.44 in patients and controls, respectively, for the UK population vs 0.66 and 0.59 in patients and controls, respectively, for the Japanese population), which is in accordance with the data deposited in HapMap (http://www.hapmap.org).

Stratification analysis of the four polymorphisms under study showed that the rs4810485 CD40 SNP was strongly associated with the presence of RF and anti-CCP antibodies $\left(\mathrm{p}=8.10 \times 10^{-6}\right.$, OR $0.82,95 \%$ CI 0.75 to 0.89 and $p=9.52 \times 10^{-5}$, OR $0.81,95 \%$ CI 0.73 to 0.90 , respectively). CCL21 rs2812378 also showed this trend, but $p$ values for the association with seropositive disease were modest ( $p=0.02$, OR 1.10, 95\% CI 1.01 to 1.18 and $\mathrm{p}=0.03$, OR 1.10, 95\% CI 1.01 to 1.21 , for RF and anti-CCP RA, respectively) (supplementary table 2 ).

Meta-analysis of these markers was undertaken, pooling data from the previously published RA GWASs, ${ }^{4} 511$ together with data from a validation cohort from the US ${ }^{11}$ and our validation study in a UK cohort. $p$ Values for the Breslow-Day test were 0.31 for rs $4810485,0.81$ for rs2812378 and 0.02 for rs42041 (table 2). The meta-analysis revealed strong evidence of association with the CD40 variant and a more modest, but suggestive association with the CCL21 variant. The evidence for association with $C D K 6$ was relatively weak.

The rs6682654 SNP mapping to CD244 and showing evidence for association with RA in a Japanese population ${ }^{12}$ was not tested in the meta-analysis by Raychaudhri et al. ${ }^{11}$ In order to investigate whether a weak effect on susceptibility could be detected in a UK population, we performed a meta-analysis of the variant, combining imputed data from the WTCCC dataset with that derived from direct genotyping in the current validation study. Pooled analysis revealed no association with RA in the UK population ( $p=0.87$, OR $1.004,95 \%$ CI 0.95 to 1.06). Joint analysis of the Japanese and UK cohorts was not feasible, due to the high degree of genetic heterogeneity between the populations $\left(\mathrm{p}_{\text {Breslow-Day }}=1.8 \times 10^{-6}\right.$ ).

\section{DISCUSSION}

In this large UK cohort, we have found strong association of the rs4810485 CD40 variant with susceptibility to RA, and weaker evidence for association with RA in the CCL21 locus. We found no evidence for association with either the CDK6 locus or the

Table 1 Validation study of novel rheumatoid arthritis (RA) susceptibility markers in a UK population

\begin{tabular}{|c|c|c|c|c|c|c|c|c|c|c|c|c|c|c|}
\hline \multirow[b]{3}{*}{ Locus } & \multirow[b]{3}{*}{ SNP } & \multirow{3}{*}{$\begin{array}{l}\text { Minor/ } \\
\text { major } \\
\text { allele }\end{array}$} & \multirow{3}{*}{$\begin{array}{l}\text { MAF } \\
\text { RA }\end{array}$} & \multirow{3}{*}{$\begin{array}{l}\text { MAF } \\
\text { controls }\end{array}$} & \multicolumn{6}{|c|}{ Genotype frequency, no (\%) } & \multirow{3}{*}{$\begin{array}{l}\text { p For } \\
\text { allele }\end{array}$} & \multirow{3}{*}{$\begin{array}{l}\text { OR }(95 \% \mathrm{CI}) \text { for } \\
\text { allele }\end{array}$} & \multirow{3}{*}{$\begin{array}{l}\text { p For } \\
\text { genotypes }\end{array}$} & \multirow{3}{*}{$\begin{array}{l}\text { p For } \\
12+22 \\
\text { vs } 11\end{array}$} \\
\hline & & & & & \multicolumn{3}{|l|}{ RA } & \multicolumn{3}{|l|}{ Controls } & & & & \\
\hline & & & & & 11 & 12 & 22 & 11 & 12 & 22 & & & & \\
\hline CD40 & rs4810485 & $T / G$ & 0.23 & 0.25 & $165(4.5)$ & $1334(36.2)$ & $2184(59.3)$ & $173(5.7)$ & 1189 (39.1) & $1681(55.2)$ & $2 \times 10^{-4}$ & $0.86(0.79$ to 0.93$)$ & 0.001 & 0.02 \\
\hline CCL21 & rs2812378 & $\mathrm{G} / \mathrm{A}$ & 0.37 & 0.35 & $478(12.9)$ & $1752(47.2)$ & $1478(39.9)$ & $377(12.5)$ & $1339(44.5)$ & $1294(43)$ & 0.04 & $1.08(1.01$ to 1.16$)$ & 0.03 & 0.65 \\
\hline CDK6 & rs42041 & $\mathrm{G} / \mathrm{C}$ & 0.25 & 0.25 & $228(6.1)$ & $1402(37.8)$ & $2079(56.1)$ & $182(6.1)$ & $1125(38)$ & $1655(55.9)$ & 0.91 & $0.99(0.92$ to 1.08$)$ & 0.99 & 0.99 \\
\hline CD244 & rs6682654 & $\mathrm{G} / \mathrm{A}$ & 0.43 & 0.44 & $638(18.1)$ & $1756(49.8)$ & $1132(32.1)$ & $571(19.9)$ & 1394 (48.5) & $909(31.6)$ & 0.20 & $0.96(0.89$ to 1.02$)$ & 0.19 & 0.07 \\
\hline
\end{tabular}

MAF, minor allele frequency; SNP, single nucleotide polymorphism.

Table 2 Meta-analysis of newly identified rheumatoid arthritis (RA) markers in populations of European ancestry

\begin{tabular}{|c|c|c|c|c|c|c|c|c|c|c|}
\hline \multirow[b]{2}{*}{ Locus } & \multirow[b]{2}{*}{ SNP } & \multicolumn{2}{|c|}{ GWAS meta-analysis ${ }^{11}$} & \multicolumn{2}{|c|}{ US validation ${ }^{11}$} & \multicolumn{2}{|c|}{ UK validation } & \multicolumn{3}{|c|}{ Meta-analysis } \\
\hline & & p Value & OR & p Value & $\mathbf{O R}$ & p Value & OR (95\% Cl) & p Value & OR (95\% Cl) & $\begin{array}{l}\text { Breslow-Day } \\
\text { p value }\end{array}$ \\
\hline CD40 & rs4810485 & $2.4 \times 10^{-7}$ & 0.83 & 0.003 & 0.91 & $2 \times 10^{-4}$ & $0.86(0.79$ to 0.93$)$ & $7.8 \times 10^{-8}$ & $0.87(0.83$ to 0.92$)$ & 0.31 \\
\hline CCL21 & rs2812378 & $6.9 \times 10^{-5}$ & 1.13 & $9.7 \times 10^{-4}$ & 1.10 & 0.04 & 1.08 (1.01 to 1.16$)$ & $1.2 \times 10^{-4}$ & 1.09 (1.04 to 1.14$)$ & 0.81 \\
\hline CDK6 & rs42041 & $5.5 \times 10^{-5}$ & 1.15 & 0.01 & 1.08 & 0.91 & 0.99 (0.92 to 1.08$)$ & 0.002 & 1.08 (1.03 to 1.14$)$ & 0.02 \\
\hline
\end{tabular}

GWAS, genome-wide association studies; SNP, single nucleotide polymorphism. 
CD244 variant, previously reported to be associated with RA in Caucasian and Japanese populations, respectively.

The CD40 and CCL21 genes both encode proteins that are involved in immune regulation. CD40 is expressed in a wide variety of immune cells, including $B$ cells, monocytes and dendritic cells, while its ligand, CD154, is expressed by activated CD4 T cells. Binding of CD154 to CD40 provides a critical stimulus for $\mathrm{B}$ cell proliferation, immunoglobulin production, isotype switching and upregulation of other costimulatory molecules including B7-related molecules. ${ }^{16}$ CD40-CD154 interaction appears to have an important role in RA, as expression of CD154 on CD4 T cells in RA promotes increased activation of CD4 $\mathrm{T}$ lymphocytes and is associated with active disease. Indeed, blockade of this pathway has been suggested as a potentially useful therapeutic approach in RA and in autoimmune disease in general. ${ }^{16} 17$ It is interesting to note that the CD40 marker was strongly associated with anti-CCP and RF-positive RA, which suggest that this polymorphism, or other/s in LD with it, could play a role in the regulation of $B$ cell response and the production of autoantibodies. The CCL21 gene encodes a protein that is a homeostatic lymphoid chemokine instrumental in the recruitment and organisation of $T$ cells and dendritic cells into secondary lymphoid organs, which participate in lymphoid tissue microanatomical organisation in RA. ${ }^{18}$ Both genes, therefore, are plausible candidates in conferring risk of RA. Although we found statistically significant evidence for association with the CCL21 locus, this would not have remained significant if a correction for multiple testing had been applied and, therefore, confirmation of this locus as an RA susceptibility region will require further investigation in other large data series.

It is becoming well established that there exists an ethnic heterogeneity of genetic susceptibility factors in RA, meaning that findings from one ethnic group may not be readily applicable to all. For example, rs2476601 in the PTPN22 gene, which is the most robustly validated RA marker in European populations after human leukocyte antigen (HLA), is not polymorphic in Asian populations. ${ }^{19}$ In contrast, polymorphisms in PADI4 are far more strongly associated with RA in Far East populations than European populations, despite having a comparable allele frequencies. ${ }^{19-21}$ Other RA susceptibility loci, such as STAT4, are common to European and Asian populations. ${ }^{92-24}$ More relevant to the current study, it has recently been reported that the CD40 and CCL21 variants tested in the present study, are not associated with RA in a Korean population. ${ }^{25}$ However, it is possible that the CD244 SNP tested in the current study is in LD with the true causative variant in the Japanese population, but not in the UK population, which could explain the lack of replication of the association of this marker.

This is the first study to test the association of CD244 with RA in a European population, but we have found no evidence for association, despite it being a functional polymorphism with a regulatory effect on the transcription of CD244. ${ }^{12}$ Insufficient power is an unlikely cause of the lack of replication, since we achieved $>98 \%$ power to detect an association with an effect size similar to that reported in the prior Japanese study ${ }^{12}$ at a $5 \%$ significance level. However, the 'winner's curse' means that effect sizes are often overestimated in the first study in which they are reported. It is possible that the effect size at this locus is smaller and that, by chance, it has not been detected in the current study. The lack of power of individual studies may be overcome by meta-analysis where published data is available and this is particularly pertinent to the CDK6 rs42041 SNP where the power to detect association in the sample set tested in the current study was low (approximately 60\%). The meta-analysis presented here yielded a statistically significant, yet modest, association ( $p=0.002$, OR $1.08,95 \%$ CI 1.03 to 1.14 ) of the CDK6 rs 42041 marker with RA susceptibility. It should be noted that we detected some heterogeneity in the effect sizes between studies ( $p_{\text {Breslow-Day }}=0.02$ ), so the pooled OR should be considered with caution and further validation in independent cohorts will be required in order to clarify the role of this variant in RA susceptibility. For the CD244 marker, by contrast, no evidence for association was detected even after pooled analysis of the UK WTCCC and validation datasets, which included approximately 5400 patients with RA and approximately 5800 healthy controls. In this case, genetic heterogeneity would appear to explain the lack of replication as allele frequencies for the rs6682654 SNP are significantly different between the Japanese and UK populations.

In the past year, the first wave of GWAS has improved our understanding of the genetic basis of common, complex diseases, including RA. These studies have made possible the identification of new RA susceptibility loci, such as those mapping to the 6q23, TRAF1/C5, PRKCQ, KIF5A, STAT4 and now CD40. However, these initial GWAS have shown that the effect sizes resulting from associations with common SNPs are modest and, therefore, the remaining RA susceptibility genes may have even smaller effect sizes. Validation studies using large sample sizes and ethnically different populations as well as meta-analysis will be essential to robustly define new potential susceptibility loci. Only then will the investment in fine mapping and functional studies be justified to identify the aetiological variants within the validated loci. In conclusion, we have validated association of CD40 rs4810485 and detected weak evidence for association of CCL21 rs2812378 with RA in a UK population, laying the foundations for further studies of the functional and genetic effects of these variants in conferring risk of disease.

\begin{abstract}
Acknowledgements We acknowledge use of DNA from the British 1958 Birth Cohort collection, funded by the Medical Research Council grant G0000934 and the Wellcome Trust grant 068545/Z/02. IT support was provided by Mark Lay, statistical advice from Mark Lunt and technical support by Paul Gilbert, Bhaneeta Lad and Stephen G Martin. Nursing support was provided by Janet Grumley, Julie Shotton and Claire Farrar. This work was supported by the Arthritis Research Campaign (arc grant reference number 17552). We would also like to acknowledge the National Health Service (NHS) Research and Development Support Fund for Guy's and St Thomas' and Lewisham NHS Trusts We acknowledge the arc, Leeds Teaching Hospitals Charitable Trustees and NIHR Leeds Musculoskeletal Biomedical Research Unit for supporting the establishment of the Leeds cohorts. We thank the Manchester Biomedical Research Centre for support.
\end{abstract}

\section{Competing interests None.}

Ethics approval This study was conducted with the approval of the North West Research Ethics Committee (MREC 99/8/84).

Provenance and peer review Not commissioned; externally peer reviewed. For more information on the WTCCC and YEAR Consortiums, see supplementary material.

\section{REFERENCES}

1. McCarthy MI, Abecasis GR, Cardon LR, et al. Genome-wide association studies for complex traits: consensus, uncertainty and challenges. Nat Rev Genet 2008;9:356-69.

2. Thomson W, Barton $A$, Ke X, et al. Rheumatoid arthritis association at 6q23. Nat Genet 2007;39:1431-3.

3. Plenge RM, Cotsapas C, Davies L, et al. Two independent alleles at $6 \mathrm{q} 23$ associated with risk of rheumatoid arthritis. Nat Genet 2007;39:1477-82.

4. Wellcome Trust Case Control Consortium. Genome-wide association study of 14,000 cases of seven common diseases and 3,000 shared controls. Nature 2007;447:661-78.

5. Plenge RM, Seielstad M, Padyukov L, et al. TRAF1-C5 as a risk locus for rheumatoid arthritis - a genomewide study. N Eng/ J Med 2007;357:1199-209.

6. Kurreeman FA, Padyukov L, Marques RB, et al. A candidate gene approach identifies the TRAF1/C5 region as a risk factor for rheumatoid arthritis. PLoS Med 2007;4:e278.

7. Zervou MI, Sidiropoulos P, Petraki E, et al. Association of a TRAF1 and a STAT4 gene polymorphism with increased risk for rheumatoid arthritis in a genetically homogeneous population. Hum Immunol 2008;69:567-71. 
8. Kurreeman FA, Rocha D, Houwing-Duistermaat J, et al. Replication of the tumor necrosis factor receptor-associated factor 1/complement component 5 region as a susceptibility locus for rheumatoid arthritis in a European family-based study. Arthritis Rheum 2008;58:2670-4.

9. Barton A, Thomson W, Ke X, et al. Re-evaluation of putative rheumatoid arthritis susceptibility genes in the post-genome wide association study era and hypothesis of a key pathway underlying susceptibility. Hum Mol Genet 2008;17:2274-9.

10. Barton A, Thomson W, Ke X, et al. Rheumatoid arthritis susceptibility loci at chromosomes 10p15, 12q13 and 22q13. Nat Genet 2008;40:1156-9.

11. Raychaudhuri S, Remmers EF, Lee AT, et al. Common variants at CD40 and other loci confer risk of rheumatoid arthritis. Nat Genet 2008;40:1216-23.

12. Suzuki A, Yamada R, Kochi Y, et al. Functional SNPs in CD244 increase the risk of rheumatoid arthritis in a Japanese population. Nat Genet 2008;40:1224-9.

13. Arnett FC, Edworthy SM, Bloch DA, et al. The American Rheumatism Association 1987 revised criteria for the classification of rheumatoid arthritis. Arthritis Rheum 1988; 31:315-24.

14. MacGregor AJ, Bamber S, Silman AJ. A comparison of the performance of different methods of disease classification for rheumatoid arthritis. Results of an analysis from a nationwide twin study. J Rheumatol 1994;21:1420-6.

15. Frazer KA, Ballinger DG, Cox DR, et al. A second generation human haplotype map of over 3.1 million SNPs. Nature 2007; 449:851-61.

16. Toubi E, Shoenfeld Y. The role of CD40-CD154 interactions in autoimmunity and the benefit of disrupting this pathway. Autoimmunity 2004;37:457-64.
17. Liu MF, Chao SC, Wang CR, et al. Expression of CD40 and CD40 ligand among cell populations within rheumatoid synovial compartment. Autoimmunity 2001;34:107-13.

18. Manzo A, Paoletti S, Carulli M, et al. Systematic microanatomical analysis of CXCL13 and CCL21 in situ production and progressive lymphoid organization in rheumatoid synovitis. Eur J Immunol 2005;35:1347-59.

19. Yamada R, Yamamoto K. Mechanisms of disease: genetics of rheumatoid arthritis--ethnic differences in disease-associated genes. Nat Clin Pract Rheumatol 2007;3:644-50.

20. Barton A, Bowes J, Eyre S, et al. Investigation of polymorphisms in the PADI4 gene in determining severity of inflammatory polyarthritis. Ann Rheum Dis 2005;64:1311-15

21. Iwamoto T, Ikari K, Nakamura T, et al. Association between PADI4 and rheumatoid arthritis: a meta-analysis. Rheumatology (Oxford) 2006;45:804-7.

22. Kobayashi S, Ikari $\mathrm{K}$, Kaneko $\mathrm{H}$, et al. Association of STAT4 with susceptibility to rheumatoid arthritis and systemic lupus erythematosus in the Japanese population. Arthritis Rheum 2008;58:1940-6.

23. Lee HS, Remmers EF, Le JM, et al. Association of STAT4 with rheumatoid arthritis in the Korean population. Mol Med 2007;13:455-60.

24. Orozco G, Alizadeh BZ, Delgado-Vega AM, et al. Association of STAT4 with rheumatoid arthritis: a replication study in three European populations. Arthritis Rheum 2008;58:1974-80.

25. Lee HS, Korman BD, Le JM, et al. Genetic risk factors for rheumatoid arthritis differ in Caucasian and Korean populations. Arthritis Rheum 2009:60:364-71. 


\section{Corrections}

The department of one of the authors who co-authored all of the below papers has found that the affiliations were not correct. The correct affiliations for Professor P Emery, for all of the below articles, are: ${ }^{1}$ Section of Musculoskeletal Disease, Leeds Institute of Molecular Medicine, University of Leeds; ${ }^{2}$ NIHR Leeds Musculoskeletal Biomedical Research Unit, Leeds Teaching Hospitals Trust, Leeds, UK.

1. Keystone E, Emery P, Peterfy CG, et al. Rituximab inhibits structural joint damage in patients with rheumatoid arthritis with an inadequate response to tumour necrosis factor inhibitor therapies. Ann Rheum Dis 2009;68:216-21.

2. Doward LC, McKenna SP, Whalley D, et al. The development of the L-OoL: a quality-of-life instrument specific to systemic lupus erythematosus. Ann Rheum Dis 2009;68:196-200.

3. Potter C, Hyrich KL, Tracey A, et al. Association of rheumatoid factor and anticyclic citrullinated peptide positivity, but not carriage of shared epitope or PTPN22 susceptibility variants, with anti-TNF response in RA. Ann Rheum Dis 2009;68:69-74.

4. Smolen JS, Han C, van der Heijde DM, et al.; Active-Controlled Study of Patients Receiving Infliximab for the Treatment of Rheumatoid Arthritis of Early Onset (ASPIRE) Study Group. Radiographic changes in rheumatoid arthritis patients attaining different disease activity states with methotrexate monotherapy and infliximab plus methotrexate: the impacts of remission and tumour necrosis factor blockade. Ann Rheum Dis 2009;68:823-7.

5. Buch MH, Boyle DL, Rosengren S, et al. Mode of action of abatacept in rheumatoid arthritis patients having failed tumour necrosis factor blockade: a histological, gene expression and dynamic magnetic resonance imaging pilot study. Ann Rheum Dis 2009;68:1220-7.

6. Emery P, Van Vollenhoven R, Ostergaard M, et al. Guidelines for initiation of antitumour necrosis factor therapy in rheumatoid arthritis: similarities and differences across Europe. Ann Rheum Dis 2009;68:456-9.

7. Bejarano V, Conaghan PG, Proudman SM, et al. Long-term efficacy and toxicity of ciclosporin A in combination with methotrexate in poor prognosis rheumatoid arthritis Ann Rheum Dis 2009;68:761-3.

8. Rudwaleit M, Landewé R, van der Heijde D, et al. The development of Assessment of SpondyloArthritis international Society classification criteria for axial spondyloarthritis (part I): classification of paper patients by expert opinion including uncertainty appraisal. Ann Rheum Dis 2009;68:770-6.

9. Bennett AN, Marzo-Ortega H, Emery P, et al.; Leeds Spondyloarthropathy Group. Diagnosing axial spondyloarthropathy. The new Assessment in SpondyloArthritis international Society criteria: MRI entering centre stage. Ann Rheum Dis 2009;68:765-7.

10. Marzo-Ortega H, McGonagle D, O'Connor P, et al. Baseline and 1-year magnetic resonance imaging of the sacroiliac joint and lumbar spine in very early inflammatory back pain. Relationship between symptoms, HLA-B27 and disease extent and persistence. Ann Rheum Dis 2009;68:1721-7.

11. Gilworth G, Emery P, Gossec L, et al. Adaptation and cross-cultural validation of the rheumatoid arthritis work instability scale (RA-WIS). Ann Rheum Dis 2009;68:1686-90.

12. Gilworth G, Emery P, Gossec L, et al. Adaptation and cross-cultural validation of the RA-WIS (Work Instability Scale). Ann Rheum Dis 2009;68:1686-90.

13. Jarrett SJ, Sivera F, Cawkwell LS, et al. MRI and clinical findings in patients with ankylosing spondylitis eligible for anti-tumour necrosis factor therapy after a short course of etoricoxib. Ann Rheum Dis 2009;68:1466-9.

14. Haugeberg G, Conaghan PG, Quinn $\mathrm{M}$, et al. Bone loss in patients with active early rheumatoid arthritis: infliximab and methotrexate compared with methotrexate treatment alone. Explorative analysis from a 12-month randomised, double-blind, placebo-controlled study. Ann Rheum Dis 2009;68:1898-901.

15. Genovese MC, Breedveld FC, Emery P, et al. Safety of biological therapies following rituximab treatment in rheumatoid arthritis patients. Ann Rheum Dis 2009;68:1894-7

16. Kekow J, Moots RJ, Emery P, et al. Patient-reported outcomes improve with etanercept plus methotrexate in active early rheumatoid arthritis and the improvement is strongly associated with remission: the COMET trial. Ann Rheum Dis 2010;69:222-5

17. Furst DE, Keystone EC, Fleischmann R, et al. Updated consensus statement on biological agents for the treatment of rheumatic diseases, 2009. Ann Rheum Dis 2010;69(Suppl 1):i2-29.

18. Freeston JE, Wakefield RJ, Conaghan PG, et al. A diagnostic algorithm for persistence of very early inflammatory arthritis: the utility of power Doppler ultrasound when added to conventional assessment tools. Ann Rheum Dis 2010;69:417-9.

19. Jones $\mathbf{E}$, Churchman SM, English A, et al. Mesenchymal stem cells in rheumatoid synovium: enumeration and functional assessment in relation to synovial inflammation level. Ann Rheum Dis 2010;69:450-7.

20. Alten RE, Zerbini C, Jeka S, et al. Efficacy and safety of pamapimod in patients with active rheumatoid arthritis receiving stable methotrexate therapy. Ann Rheum Dis 2010;69:364-7.
21. Machold KP, Landewé R, Smolen JS, et al. The Stop Arthritis Very Early (SAVE) trial, an international multicentre, randomised, double-blind, placebo-controlled trial on glucocorticoids in very early arthritis. Ann Rheum Dis 2010;69:495-502.

22. Schoels M, Knevel R, Aletaha D, et al. Evidence for treating rheumatoid arthritis to target: results of a systematic literature search. Ann Rheum Dis 2010;69:638-43.

23. Smolen JS, Aletaha D, Bijlsma JW, et al.; T2T Expert Committee. Treating rheumatoid arthritis to target: recommendations of an international task force. Ann Rheum Dis 2010;69:631-7.

24. Burr ML, Naseem H, Hinks A, et al.; BIRAC Consortium; YEAR Consortium. PADI4 genotype is not associated with rheumatoid arthritis in a large UK Caucasian population. Ann Rheum Dis 2010;69:666-70.

25. Emery $\mathbf{P}$, Durez P, Dougados $\mathrm{M}$, et al. Impact of T-cell costimulation modulation in patients with undifferentiated inflammatory arthritis or very early rheumatoid arthritis: a clinical and imaging study of abatacept (the ADJUST trial). Ann Rheum Dis 2010;69:510-16.

26. Bennett AN, Rehman A, Hensor EM, et al. The fatty Romanus lesion: a noninflammatory spinal MRI lesion specific for axial spondyloarthropathy. Ann Rheum Dis 2010;69:891-4.

27. Nam JL, Winthrop KL, van Vollenhoven RF, et al. Current evidence for the management of rheumatoid arthritis with biological disease-modifying antirheumatic drugs: a systematic literature review informing the EULAR recommendations for the management of RA. Ann Rheum Dis 2010;69:976-86.

28. Smolen JS, Landewé R, Breedveld FC, et al. EULAR recommendations for the management of rheumatoid arthritis with synthetic and biological disease-modifying antirheumatic drugs. Ann Rheum Dis 2010;69:964-75.

29. Tan RJ, Gibbons LJ, Potter C, et al.; BRAGGSS. Investigation of rheumatoid arthritis susceptibility genes identifies association of AFF3 and CD226 variants with response to anti-tumour necrosis factor treatment. Ann Rheum Dis 2010;69:1029-35.

30. Robinson JI, Barrett JH, Taylor JC, et al.; YEAR Consortium; BRAGGSS. Dissection of the FCGR3A association with RA: increased association in men and with autoantibody positive disease. Ann Rheum Dis 2010;69:1054-7.

31. Cohen SB, Keystone E, Genovese MC, et al. Continued inhibition of structural damage over 2 years in patients with rheumatoid arthritis treated with rituximab in combination with methotrexate. Ann Rheum Dis 2010;69:1158-61.

32. Haugeberg G, Bennett AN, McGonagle D, et al. Bone loss in very early inflammatory back pain in undifferentiated spondyloarthropathy: a 1-year observational study. Ann Rheum Dis 2010;69:1364-6.

33. Schoels M, Aletaha D, Smolen JS, et al. Follow-up standards and treatment targets in rheumatoid arthritis: results of a questionnaire at the EULAR 2008. Ann Rheum Dis 2010;69:575-8

34. Eyre S, Flynn E, Martin P, et al. No evidence for association of the KLF12 gene with rheumatoid arthritis in a large UK cohort. Ann Rheum Dis 2010;69:1407-8.

35. Eyre S, Hinks A, Flynn E, et al. Confirmation of association of the REL locus with rheumatoid arthritis susceptibility in the UK population. Ann Rheum Dis 2010;69:1572-3

36. Orozco G, Eyre S, Hinks A, et al.; Wellcome Trust Case Control consortium YEAR Consortium. Association of CD40 with rheumatoid arthritis confirmed in a large UK case-control study. Ann Rheum Dis 2010;69:813-16.

37. Emery $\mathbf{P}$, Durez P, Dougados $M$, et al. Impact of T-cell costimulation modulation in patients with undifferentiated inflammatory arthritis or very early rheumatoid arthritis: a clinical and imaging study of abatacept (the ADJUST trial). Ann Rheum Dis 2010;69:510-16

38. Saleem B, Keen $\mathrm{H}$, Goeb V, et al. Patients with RA in remission on TNF blockers: when and in whom can TNF blocker therapy be stopped? Ann Rheum Dis 2010;69:1636-42.

39. Barkham N, Coates LC, Keen H, et al. Double-blind placebo-controlled trial of etanercept in the prevention of work disability in ankylosing spondylitis. Ann Rheum Dis 2010;69:1926-8.

40. Emery P, Deodhar A, Rigby WF, et al. Efficacy and safety of different doses and retreatment of rituximab: a randomised, placebo-controlled trial in patients who are biological naive with active rheumatoid arthritis and an inadequate response to methotrexate (Study Evaluating Rituximab's Efficacy in MTX iNadequate rEsponders (SERENE)). Ann Rheum Dis 2010;69:1629-35.

41. Dixon WG, Hyrich KL, Watson KD, et al.; BSRBR Control Centre Consortium; British Society for Rheumatology Biologics Register. Influence of anti-TNF therapy on mortality in patients with rheumatoid arthritis-associated interstitial lung disease: results from the British Society for Rheumatology Biologics Register. Ann Rheum Dis 2010;69:1086-91. 